\title{
Linguistic Risk-Taking: A Bridge Between the Classroom and the Outside World
}

\author{
Ed Griffiths \\ University of Ottawa \\ Nikolay Slavkov \\ University of Ottawa
}

\begin{abstract}
This article describes an initiative launched at a Canadian bilingual university in order to encourage L2 French and L2 English learners to take 'linguistic risks': authentic, autonomous communicative acts where learners are pushed out of their linguistic comfort zone. The initiative was operationalized through the development of a Linguistic RiskTaking Passport, which contains 74 linguistic risks that students can take in their L2 across the university campus and in their everyday life. An analysis of interviews with participating teachers $(n=6)$ and learner self-report data from completed passports $(n=410)$ examines how the initiative was integrated into the classroom and which passport items were perceived by students as particularly high-risk. A cyclical process of risk-taking within a broad TaskBased Language Teaching (TBLT) framework is described in which risks are viewed as learner-selected tasks with a dynamic affective slant; risks can be used to connect classroom learning with real-life L2 use and vice versa. The data illustrate that linguistic risk-taking can help TBLT practitioners generate ideas on how to narrow the gap between the classroom and the real-world. The article concludes with a list of practical implications and suggestions for adapting linguistic risk-taking to other institutional contexts.
\end{abstract}

\section{Résumé}

Cet article s'intéresse à une initiative lancée à une université bilingue canadienne afin d'encourager les apprenants de L2 française et de L2 anglaise à prendre des « risques linguistiques », définis comme des actes communicatifs authentiques et autonomes où les apprenants sont poussés hors de leur zone de confort linguistique. L'initiative a été mise en place par le développement d'un Passeport de prise de risques linguistiques, qui contient 74 risques linguistiques que les étudiants peuvent prendre en utilisant leur L2 sur le campus universitaire et dans leur vie quotidienne. Une analyse des entretiens avec les enseignants ayant participé $(n=6)$ et des données d'autoréflexion recueillies à partir des passeports remplis par des apprenants $(n=410)$ examine comment l'initiative a été intégrée dans la salle de classe et quelles activités du passeport ont été perçues par les étudiants comme ayant un niveau de risque particulièrement élevé. Nous présentons un processus cyclique de prise de risque dans le cadre général d'une approche d'Apprentissage des langues basé sur les tâches (ALBT) dans lequel les risques sont considérés comme des tâches avec une orientation affective et dynamique et sont choisies par l'apprenant; les risques peuvent être utilisés pour faire le lien entre l'apprentissage dans la salle de classe et l'utilisation de la L2 dans la vie quotidienne et vice versa. Les données indiquent que la prise de risques linguistiques peut 
aider les professionnels de l'enseignement des langues qui utilisent l'approche ALBT à générer des idées sur la manière de réduire l'écart entre la salle de classe et le monde réel. L'article se termine par une liste d'implications pratiques et de suggestions pour adapter la prise de risque linguistique à d'autres contextes institutionnels.

\section{Linguistic Risk-Taking: A Bridge Between the Classroom and the Outside World}

It has been said that "you take a risk every time you open your mouth in a foreign language" (Beebe, 1983, p. 89). On the one hand, this sense of risk is related to potential discomfort or anxiety caused by factors such as fear of making errors, (perception of) failing to be understood or to understand others, loss of face or identity, the inability to socialize with others, etc. (see MacIntyre, 2017, for an overview of social, cognitive and academic factors related to language anxiety). On the other hand, L2 speakers may also attest to the transformative power of overcoming such challenges: tasks achieved, meaningful connections made, self-esteem raised, or enjoyment felt (see, for example, Dewaele \& MacIntyre 2016; Dewaele et al., 2018). ${ }^{1}$ This article reports on a project entitled 'The Linguistic Risk-Taking Initiative' launched at the University of Ottawa, the largest Canadian bilingual (French-English) postsecondary institution, to capitalize on the potential benefits of taking risks in an L2. The goal of the article is twofold: 1) to bring linguistic risk-taking to the attention of TBLT researchers and practitioners, arguing that linguistic risks are types of tasks with special characteristics and with potentially interesting implications for the field; and 2) to report the results of an exploratory study on linguistic risk-taking from a TBLT perspective. The overall research problem we explore is how we can better connect the outside world with the L2 classroom and vice versa, with the help of linguistic risk-taking tasks.

\section{The Linguistic Risk-Taking Initiative}

\section{The Passport}

A core part of the initiative we describe is a 'Linguistic Risk-Taking Passport' which was designed for students taking English or French as a second language courses at the University of Ottawa. The passport was not based on a single theory or approach but inspired by a mixture of theoretical frameworks, as well as by individual learner and teacher experiences. It drew on: a) the foundations of language socialization and second language socialization theory (Duff, 2017; Duff \& Talmy, 2011; Ochs and Schieffelin, 2008 ) in emphasizing authentic, contextually embedded, naturally occurring interactions in the community as an important conduit of L2 development; b) positive psychology (Csikszentmihalyi \& Nakamura, 2011; MacIntyre \& Mercer, 2014) in positioning language learning as part of the study of how humans thrive and what they enjoy doing; and c) cognitive theories relating to interaction (Gass \& Mackey, 2015; Long, 1996) also associated with TBLT. ${ }^{2}$

In practical terms, the design of the passport involved the creation of a list of situations or contexts in which language learners may find themselves engaged in, throughout their everyday lives on the bilingual campus and beyond. This formed the basis for over seventy suggestions for L2 risks contained in the passport, including ordering at 
the university cafeteria, writing to a professor in their second language, changing the language of their smartphone to their L2, using their L2 at a job interview or at a party, etc.

For our purposes, a risk is defined as an authentic, autonomous communicative act where learners are pushed out of their linguistic and cultural comfort zone (Slavkov \& Séror, 2019). Risks are associated with the discomfort of doing things that learners hesitate to do in their L2 in the real world because they may lack the necessary linguistic or cultural competence, experience, or habit. As such, when given the choice, learners may prefer to stay within the comfort zone of their L1, especially on a bilingual campus where courses, services, and events allow users to choose their preferred language (or learners may choose to remain silent and not engage in various real-life activities.) In other words, learners can simply avoid using the L2 in authentic situations outside of the walls of the L2 classroom despite the numerous real-life opportunities at their fingertips. Of course, linguistic risks can also be taken in class. However, the passport we designed focuses specifically on fostering language use outside of the classroom as the ultimate goal of language learning.

In adopting and further developing the notion of risk, we purposefully did not restrict the passport to spoken interactions, although it may well be that such situations involve a higher degree of discomfort in the L2 for many learners. We made this choice because we believe that engaging in the traditional skills of listening, reading and writing in the L2 also carries risk value. Even seemingly passive technological interactions such as switching the language of a smartphone to the L2 can be risky if paying a bill using a banking app or registering for a university course, etc. These are examples of relatively high-stakes situations where an error due to incomplete L2 competence can have important consequences. However, linguistic risks are not limited to high-stakes activities. Reading a book, watching a movie or receiving daily news in the L 2 can involve various feelings of discomfort with the L2, such as incomplete comprehension, a sense of a lower level of efficiency in our daily transactions, or feeling socially or linguistically less adept. We, therefore, adopted a broad and multidimensional definition of linguistic risks and included a wide variety of communicative situations in which we wanted to encourage learners to engage through our project.

Additionally, we recognized that different situations may carry different risk values for learners. Therefore, we left it to the learners themselves to determine which items listed in the passport constituted high, medium, or low risk for them and asked them to indicate this, using checkboxes, in the passport for the risks they decided to take. Most risks in the passport were designed to be taken up to three times (i.e., three checkboxes were available) to encourage some repetition for pedagogical purposes. Learners were asked to complete at least 20 risks over the course of a semester in order to be entered into a prize draw. There were no specific requirements as to which risks they chose; in other words, learners were free to choose only risks that were relevant to them in recognition that they must be agents in their own learning. We also recognized that the notion of risk is subject to complex individual differences and that some of the items in the passport may constitute risk for some learners but not for others (see also section 3 ). To this end, learners were specifically instructed to select only items that represented risk for them and not simply daily activities that they were comfortable doing and that constituted no challenge to them in the L2.

Sample pages from the English version of the Linguistic Risk-Taking Passport are shown in Figure 1. ${ }^{3}$ 


\section{Figure 1}

Sample Risk-Taking Pages from the English Version of the Linguistic Risk-Taking Passport

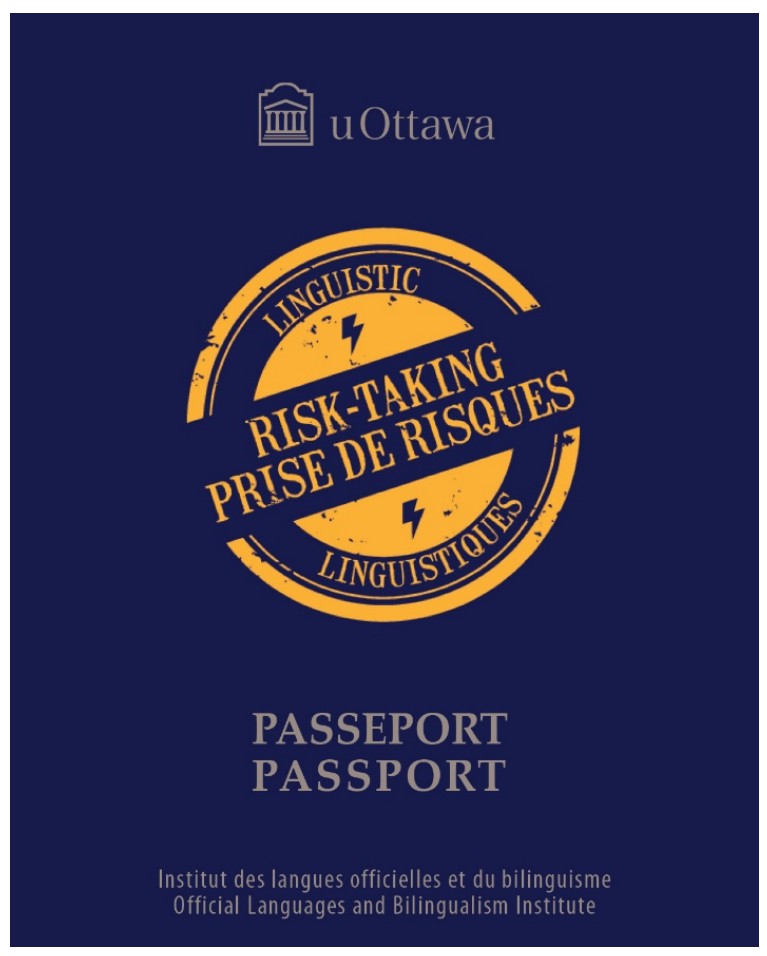

\section{LINGUISTIC RISKS}

Most risks can be repeated up to three times (see num ber of checkboxes by each risk); no particular order is required; please rate each risk as High (H), Medium (M) or Low (L) each time you undertake it.
Example: I read the rules of engagement of the linguistic risk-taking passport.

1. I attended an event on campus (e.g. activity, lecture, etc.) in English.

2. I ordered food on campus in English.
3. I used English at uOttawa's Health Services.

4. I sent an email to a uOttawa professor in English.

5. I sent an email to a uOttawa staff member in English.

6. I spoke English at the Julien Couture Resource Centre (MHN 02).

7. I borrowed English material from the Julien Couture Resource Centre.

Comments:
Comments:$$
\text { Comments: }
$$

$\nabla L$

$\square$.....
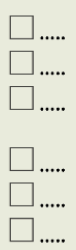
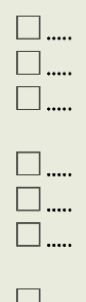
The passport also contained pages explaining to learners what linguistic risks are, why it is important to take risks, and how to participate in the initiative. Additional pages allowed learners to propose risks that were not already included in the passport. Comment pages and an end-of-term self-assessment page were also included. Motivational statements and slogans (e.g., "I am eager to use my second official language everywhere on campus and beyond! Yes, I may have an accent but that's what makes me unique! I am not afraid of making errors because they are natural and normal in language use! I consider myself bilingual in French and English even if one of my two official languages may be stronger than the other one!') were featured in the passport as well.

The current article focuses only on certain features of the passport and only a subset of the data from the larger project will be discussed and analyzed (see section 4). Readers are also directed to Slavkov (2020) and Slavkov and Séror (2019) for a more detailed description of the project's origins and operationalization.

\section{Teachers' Role}

Academic freedom provisions at our institution stipulate that no particular teaching method or approach is required. Thus, language teachers are free to draw on their individual teaching philosophy in meeting curriculum objectives. French and English language teaching may also be influenced by pedagogical frameworks that are more prominent in the literature or current trends in that specific language. For example, French teachers may be more familiar and adopt the principles and tools of l'approche actionnelle (the action-oriented approach; Council of Europe 2001, 2018), drawing on ideas of plurilingualism (Coste et al., 2009), among others. English teachers may be more familiar with and influenced by TBLT, among others. Nonetheless, various approaches and ideas cross-pollinate among teachers through staff meetings and professional development in either language.

With this context in mind, we conceptualized the Linguistic Risk-Taking Initiative and put out a call for interested practitioners to participate. We did not overtly orient to or recommend a specific approach in explaining the objectives and the procedures of the initiative but offered in-class presentations of the project and follow-up meetings to support teachers. Some teachers decided to simply allow the distribution of the passports and let students make use of them on their own, without specific classroom preparation or follow-up. Others chose to integrate the project into their classroom teaching. In this article, we focus on the latter.

\section{Theoretical Background}

\section{Linguistic Risk-Taking, Willingness to Communicate, Language Anxiety and Language Enjoyment}

Kogan \& Wallach (1967) cited "lack of certainty and the prospect of loss or failure" (p.167) as central to the perception of certain behaviours as risky. Nevertheless, taking risks is a fundamental human characteristic and occurs on a daily basis (Beebe, 1983, among others). It is reasonable to assume that if a learner is hesitant to engage in the L2 in real life in certain specific situations, targeting exactly these situations may result in 
additional language exposure and practice. Through risk-taking, the L2 may thus be used in a larger number of domains, ultimately also leading to a higher level of competence and confidence. 'Healthy risk-taking' can be supported in classroom environments by language teachers willing to "provide contexts in which learners can take risks", which can, in turn, mediate positive language outcomes (Cervantes, 2013, p. 433). Our passport, which has a classroom-external focus, offers opportunities for learners to target linguistic risks in real life but also invites classroom support.

Linguistic risk-taking is related to the well-known notion of Willingness to Communicate (WTC), defined as "a state of readiness to engage in the L2, the culmination of the processes that prepare the learner to initiate the L2 communication process" (MacIntyre et al., 2011, p. 82). WTC is a fluctuating, dynamic state (MacIntyre, 2012), itself tied to interrelated theoretical concepts, such as language anxiety and motivation. Linguistic risk-taking is closely related to WTC in its fundamentally dynamic nature. Our pedagogical initiative described in section 2 capitalizes on this aspect in recognizing that what may be a risk for one learner may not be risky for another; even for the same learner a situation that is identical on the surface (e.g., ordering food at the cafeteria) may be perceived as high-risk at one time and as moderate or low risk at another time. Like WTC, linguistic risk-taking is linked to the extensive literature on anxiety and motivation, as it relates to both the discomforts of language learning and to ways of overcoming these discomforts. However, a key difference between WTC and linguistic risk-taking is that the former is a broader construct. WTC may be affected by a larger number of factors and thus interacts with a higher number of variables. For example, learners may not be willing to communicate because, at a given time, they feel tired, a communicative topic is irrelevant to them, or interpersonal/intergroup attitudes unrelated to the notion of risk are at play (see, for example, the classic pyramid model proposed by MacIntyre et al., 1998). Our operationalization of risk-taking, on the other hand, has a more limited scope because it focuses on the feeling of risk. At the same time, the construct of linguistic risk-taking differs from language anxiety in that it also adds the element of enjoyment in overcoming anxiety or more generally overcoming challenges. Overall, linguistic risk-taking encapsulates both anxiety-inducing and pleasure-inducing aspects of language learning (see also Dewaele et al., 2018, on the relationship between enjoyment and anxiety) and is a narrower construct than WTC.

An additional incentive to capitalize on linguistic risk-taking for our initiative comes from our belief that WTC is more academic in nature and associated more often with understanding human behaviour in regard to L2. ${ }^{4}$ For our purposes, linguistic risktaking is not only a narrower theoretical construct but also a catchier term for pedagogical purposes - a construct we assumed learners and teachers would be able to relate to.

\section{Positive Psychology and Emotions}

As indicated earlier, the Linguistic Risk-Taking Initiative draws in part on positive psychology. Positive emotions have come to the fore in the application of the study of how people thrive and flourish, and how ordinary human strengths and virtues contribute to general well-being (Csikszentmihalyi \& Nakamura, 2011; Dewaele et al., 2018; Lopez \& Snyder, 2009; Peterson, 2006; Seligman \& Csikszentmihalyi, 2000). Positive psychology is thus an empowering framework for building language learning skills by facing 
challenges, and by deriving pleasure and a sense of accomplishment from doing so, ultimately leading to linguistic gains and to general well-being. Positive psychology also steers away from a historical focus on negative emotions associated with L2 learning to nurture positive emotions such as engagement, appreciation, resilience and perseverance (Dewaele et al., 2018). Positive dynamics in SLA may be especially fostered "in settings in which communication and personally meaningful interactions are foregrounded" (MacIntyre \& Mercer, 2014, p. 156). This approach calls for an 'emotional turn' in SLA which rejects learners as "mere bunches of variables" (Dewaele, 2005, p. 369) and advocates for viewing emotion as a key aspect of human cognition. The relevance of this theoretical perspective to our project resides in the notion of healthy risk-taking which involves becoming aware of challenges and specifically targeting these challenges in order to seek enjoyment in overcoming them. Additionally, we leverage the ideas of positive psychology in the project's overt orientation to the real world.

\section{Beyond Classroom Learning, Language Autonomy, and (Second) Language Socialization}

According to Dewaele (2005), postmodernist researchers "are less interested in the acquisition process within the classroom walls than in the usage of that new language outside school in authentic interactions with target language speakers" (p. 369). Learning opportunities beyond the classroom include out-of-class reading, watching television, playing games, and numerous other interactive activities which have been made vastly more available with the advent of the internet and social media, as well as study abroad and community language centres (Benson \& Reinders, 2011; Nunan \& Richards, 2015). According to Littlewood (1999) "autonomy would appear to be an incontrovertible goal for learners everywhere, since it is obvious that no students, anywhere, will have their teachers to accompany them throughout life" (p.73). This does not mean that the language classroom must forgo informal or unstructured learning. For example, Jackson (2018) argues that in the context of study abroad not all learners engage sufficiently with the target language outside of the classroom and that specific interventions are necessary to support learning in both linguistic and cultural domains. ${ }^{5}$ As such, the concept of language autonomy is inextricably linked with beyond classroom learning but is also supported or fostered within the classroom. Autonomy can be facilitated by the design of curricula that encourage learners to set their own goals, bring real-world tasks into the classroom and place a strong focus on learner reflection (Cotterall, 2000). Similarly, the Linguistic RiskTaking Passport was designed as a tool that focuses on meaningful L2 use outside of the classroom but fosters in-class support and instruction.

There has been a recent tendency towards examining more social and collaborative approaches to autonomy (Benson, 2011) through which the learner enters into a more multidimensional form of learning. Conceptualizing learners as social agents plays a central role in the theory of (second) language socialization, itself an interdisciplinary theory drawing on anthropological study of the learning potential encountered in social mediation. Duff \& Talmy (2011) describe one of the primary functions of L2 language socialization as follows: "social interaction with more proficient members of a particular community [which] centrally mediates the development of both communicative competence and knowledge of the values, practices, identities, ideologies and stances of 
this community" (p. 98). Accordingly, it is by moving from the classroom to taking risks autonomously within an authentic language community that the learner may acquire both communicative ability and the knowledge of sociopragmatic and sociocultural aspects of language.

\section{TBLT and Linguistic Risk-Taking}

\section{Connections with the Real World, Agency and Engagement}

Long (1985) described a task as any of "the hundred and one things people do in everyday life, at work, at play and in-between" (p.89). We find this statement an inspiring point of departure for this article, and also a point of overlap with some of the rationale for the creation of the Linguistic Risk-Taking Initiative described earlier. One of the foremost challenges in TBLT has lain in defining further the nature of a task. Ellis and Shintani (2014) employ the following criteria to distinguish a task: a primary focus on meaning, the existence of some kind of information gap, a reliance on learners' own (linguist and nonlinguistic) resources, and a defined communicative outcome. They further acknowledge that these criteria are a continuum (i.e., some 'workplans' may be more task-like than others). In the theory and practice of TBLT over the years, the link to real-world activities has also been explored in the sub-categorization of real-world tasks (or 'target tasks'), in apposition to pedagogical tasks (Nunan, 2010). Some TBLT approaches make explicit the need to link the real world with the pedagogical, in making connections between pedagogical tasks and the corresponding real-world tasks (Nunan, 1991; Nunan \& Lockwood, 1991). Nunan further divided pedagogical tasks into rehearsal and activation tasks; the first with a 'transparent' link to the real world and the second with only an 'indirect' link (Nunan, 2004, 2010). Though Nunan's developmental sequence for the creation of task-based materials does not move beyond the classroom, he acknowledged that rehearsal sequences could be realized in some contexts by students performing the task in the real world. We will argue that the Linguistic Risk-Taking Passport is a pedagogical tool that can fulfil this real-world realization by offering opportunities for engaging and innovative connections between the classroom and the real world.

Experiential learning is another important element to consider. Ellis et al. (2020) devoted a chapter (Chapter 6) to viewing TBLT from an experiential learning perspective. In 'learning by doing', personal investment - wanting to complete the task - is key. In other words, the achievement of the task is the task, and all resources, both cognitive and affective, are channelled into its completion. Tasks may thus be viewed as transactions in which learners achieve meaningful objectives related to the real world, becoming interested and personally invested agents in their own learning.

A focus on learner-initiated activity goes some way to redressing the way in which the learner's personal interest has not always been a primary consideration in more traditional cognitive and instructed SLA approaches to TBLT (Ellis et al., 2020). This in turn has led to a body of work on promoting "task engagement", or "how teachers and course designers can expediently configure and implement communication tasks to meet learners' affective needs and generate the type of personal investment that mastering the fluent use of an L2 requires" (Lambert, 2017, p. 657). An increased focus on learner agency in TBLT leads Ellis et al. (2020) to add personal investment to their list of TBLT 
principles, advocating for this agentive role for learners and the incorporation of learners' personalities and selves into the task. The Linguistic Risk-Taking Passport described in section 2 offers some promising avenues in this direction (e.g., letting learners choose risks that are relevant to them, empowering them as agents to pursue these risks outside of the classroom, offering them rewards, etc.).

\section{Risks versus Tasks}

Consistent with Ellis \& Shintani's (2014) task criteria, the primary focus in taking a linguistic risk is on meaning, rather than form; risk-takers must certainly rely on their own resources, and the communicative outcome is the achievement of the task itself. The information gap dimension is anchored in the dynamics of the real world (e.g. finding the necessary information to complete the task of inquiring about food options at the cafeteria, asking a passer-by for directions, or emailing a professor with a specific request). As such, linguistic risks fall within the continuum of task criteria.

As already indicated, our development of the concept of risk also draws on Nunan's $(2004,2010)$ idea of tasks with transparent links to the real world. However, risks also orient to emotional or affective aspects, which makes them a special subset of tasks, as indicated in Figure 2.

\section{Figure 2}

Risks as a Subcategory of Tasks

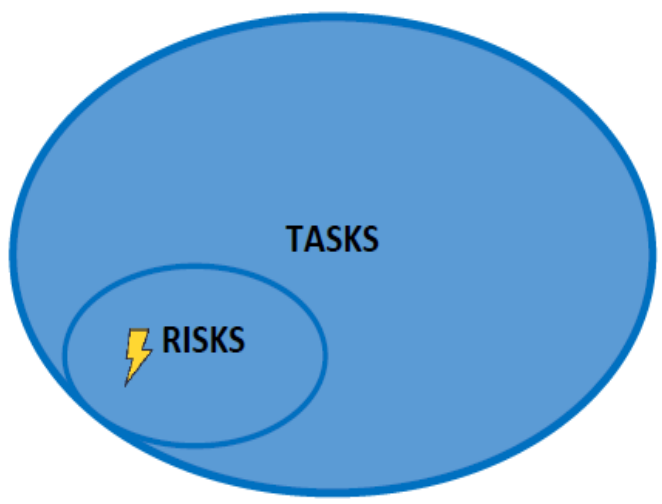

We believe this conception brings a certain new dimension to TBLT or at least addresses possible gaps in previous thinking and practice. As Ellis et al. (2020) point out, TBLT's focus "has been primarily on the cognitive dimension of learning" (p. 172), even though it is also compatible with experiential learning. In this sense, the notion of risk can add value to the TBLT field by highlighting tasks with experiential and emotional aspects. Defining risks as a special category of tasks raises questions related to individual learner variables. As indicated earlier, risks are dynamic. What some learners perceive as a risk would be perceived as just a task by others. In this sense, it becomes difficult to define $a$ priori which tasks fall within the subcategory of risks indicated in Figure 2. It is precisely for this reason that the operationalization of risks in the Linguistic Risk-Taking Passport is learner-driven. The passport explains to learners the concept of risk and asks them to choose what constitutes risk for them from an extensive list of items, and to engage in 
taking those risks. ${ }^{6}$ Thus, while the 74 risks contained in the passport were selected by faculty and teaching staff as appropriate to the pedagogical and social context of the institution, learners were instructed to choose risks that are relevant to them (also recall that learners are not asked to attempt all items form the passport). Additionally, learners were encouraged to suggest other risks that may not be listed in the passport. In this way, risks may be seen as learner-selected and learner-generated tasks (cf. Lambert et al., 2017). This important dimension of learner agency, identified by Ellis et al. (2020) as a relatively recent focus in TBLT, is also reflected in the core rationale and design of the passport.

To summarize, within the view that TBLT is "not a monolithic, tightly defined approach but quite diverse" (Ellis et al., 2020, p. 2) we believe that bringing risks to the attention of TBLT theorists and practitioners is a worthwhile endeavour.

\section{The Study}

\section{Research Questions}

This study aimed to generate initial insights into the classroom implementation of the Linguistic Risk-Taking Initiative and the student experience of risk-taking. Research questions were formulated as follows:

RQ1. What themes emerged from interviews with teachers participating in the Linguistic Risk-Taking Initiative regarding its implementation in the classroom? RQ2. Which items in the passport (i.e., tasks as defined in section 4.2) were evaluated as particularly high-risk by the students participating in the initiative? RQ3. What pedagogical implications can be drawn from insights generated through RQ1 and RQ2?

In our specific context, all three questions were intended to help improve the implementation of the project by creating recommendations for classroom practices at our institution. On a broader level, the study aims to share insights and innovative practices beyond the University of Ottawa and offer TBLT practitioners the opportunity to explore linguistic risk-taking in their own contexts.

\section{Methodology}

RQ1 was addressed through a qualitative analysis of interviews conducted by the first author of this article with language teachers who had used the Linguistic Risk-Taking Passport in their French or English language classes. This part of the study was divided into two phases. In phase 1, two unstructured pilot interviews were conducted (one with an English teacher and one with a French teacher). The purpose of these interviews was to engage in informal idea exchanges which would facilitate the creation of a research protocol with specific questions for the next phase. In order to increase spontaneity, these preliminary interviews were not audio-recorded. The researcher took detailed field notes and used them in the creation of the research protocol for phase 2. In phase 2, a protocol with questions for semi-structured interviews was established (Appendix A). The choice of semi-structured format was motivated by the fact that the participants were known to the 
researcher in a professional capacity, lessening the need for a fully directed structure that may be preferable with a stranger (Wei \& Moyer, 2008). The protocol was designed to investigate multiple research interests but focused on the active role of the instructors in establishing the passport within their language classes. To this end, only teachers who had indicated that they integrated the Linguistic Risk-Taking Passport in their classroom practices (instead of only distributing the passports to learners without any classroom support) were invited to participate (recall section 2). Six teachers responded to this invitation and participated in semi-structured interviews which were audio-recorded. In total, 208 minutes of recordings were made. The interviews were transcribed, and descriptive coding (Saldaña, 2016) was applied in order to assign basic labels to the data which would then serve for subsequent analysis. Coding was done using NVivo 12 Pro and involved a cyclical process where codes were changed, re-assigned, merged or split until a list of categories was created. Drawing on Saldaña's guidelines for theming the data, category labels (usually a word or a short phrase) were then expanded to themes that represent longer phrases or sentences in a thematic analysis framework (Auerbach \& Silverstein, 2003; Boyatzis, 1998).

RQ2 was answered by descriptive quantitative analysis of data collected from learner passports submitted during four semesters between Fall 2017 and Winter 2019. Risk levels (High/Medium/Low or Élevé/Moyen/Faible) for each risk taken by a user were coded numerically (3=High/Élevé; 2=Medium/Moyen; 1=Low/Faible). Risks that were checked off by the student without indicating a risk level were coded as 0 (missing data). For this study, only risks where the user had indicated a risk level were analyzed $(n=14,486 ; 76.4 \%$ of total risks taken over four semesters) and the remaining data $(23.6 \%)$ were excluded. The choice to remove these data was made to ensure that learners had indeed regarded the items as risks, rather than tasks with no risk element. ${ }^{7}$ As this research question concerned particularly high-risk tasks, for each of the risks in the passport $(n=61$ for the Fall 2017 semester; $n=74$ for all semesters thereafter) the proportions of the number of times a risk was marked as $\mathrm{H}$ by users was calculated against the number of times it was taken and marked $\mathrm{H}, \mathrm{M}$ or $\mathrm{L}$. This proportion (rather than using raw numbers) was chosen to reduce biases against risks that were more popular; in other words, this allowed us to examine which items were considered inherently riskier, rather than items being marked $\mathrm{H}$ simply because the type of situation they involved was a popular choice.

RQ3 is a summary question drawing on the findings of the first two questions. As such, we use critical interpretation of the findings to RQ1 and RQ2 to propose practical implications for future iterations of the pedagogical activities that are part of this ongoing project at our institution. We also use this research question as an opportunity to offer suggestions to TBLT practitioners who may be interested in adopting insights from our experience and potentially designing their own linguistic risk-taking initiatives, suitable to their particular institutional and pedagogical contexts.

\section{Participants}

The six teachers who were interviewed for this study had a range and depth of experience with the passport. Four were teachers of English and two were teachers of French. Four had used the passport with multiple classes, while two had used the passport for one semester only at the time of interview. As indicated in section 2, there were no 
prescribed top-down requirements for the instructors in how exactly to use the passport (although suggested guidelines for its effective implementation were provided). We were thus aware that the data were likely to yield evidence of a range of teaching approaches and different teaching styles.

The language learner participants in the four semesters studied $(n=426)$ were all students in English or French as a Second Language undergraduate or pre-sessional undergraduate courses at an intermediate-advanced level. ${ }^{8}$ Due to the self-report nature of the data, the question arises as to whether all learners completed their passports genuinely or whether some did it just to be entered in a prize draw or to please their teachers. Teachers generally provided only a participation credit for this project and some teachers additionally provided opt-out alternatives. No additional credit was given for an increased level of participation. We believe that this reduces the likelihood of meaningless passport submissions. Furthermore, we established a protocol for detecting anomalous and unusual use of the passport. This included identifying learners who checked off an unusually high number of risks without providing meaningful comments in the optional comment spaces, learners who checked off large chunks of sequentially numbered items rather than items interspersed in the passport, and learners who reported an unrealistic number of repetitions for specialized types of activities (e.g., seeing a play at a theatre three times in a single semester). Following this process, 16 participants (3.7\%) were excluded as unreliable data (e.g., users who had possibly completed the passport mechanically or who had not understood the instructions). Of the remaining total number of participants analyzed $(n=410), 57 \%(n=233)$ were French learners and 43\% $(n=177)$ were English learners.

\section{Results (RQ1): What Themes Emerged from Interviews with Teachers Participating in the Linguistic Risk-Taking Initiative Regarding its Implementation in the Classroom?}

The themes that emerged from the data were multifaceted; various aspects or subthemes brought up by the individual teachers were taken as a whole to contribute to an overarching theme. The themes also overlapped in some cases, with aspects potentially relating to more than a single theme. The six instructors are identified with a letter of the alphabet (teacher A-F). Teacher E was interviewed in French; all other teachers were interviewed in English. Nonetheless, spontaneous use of both languages occurred occasionally within a single interview. Transcriptions are given unedited in the language of the original interview with English translation, as appropriate.

\section{Theme 1: Classroom Support: Helping Students to Take Linguistic Risks Beyond the Classroom and to Build Autonomy}

Discussing the implementation of the Linguistic Risk-Taking Initiative with the teachers triggered rich and varied comments about classroom support and how that was aimed at developing learners' autonomy and ability to use the L2 in challenging authentic situations outside the classroom. Teachers reported that they used various activities in the classroom to achieve this, including discussions in small groups or as a class, student presentations, reflective or self-assessment questionnaires, reflective essays or other compositions, role-plays, goal setting activities, risk-taking buddy schemes, visualizations 
of an ideal L2 self, and inner voice/mindset activities. These were incorporated to a different degree by the different teachers depending on their own teaching philosophy. The overarching theme of support was multifaceted, consisting of three different dimensions or subthemes, including 1) emotional and motivational support; 2) strategic support; and 3) linguistic support.

Starting with emotional and motivational support, several teachers offered classroom advice to learners, often recalling their own experiences as language learners and their own struggles using the L2.

Example 1:

Realizing that your teachers also struggle, your friend also struggles, the dean also struggles, everybody struggles. Life is a struggle...on a very positive note! I think it's useful to discuss it. As a group, we can brainstorm ideas, strategies. In the end, we're like, "Okay, it wasn't that bad."

(Teacher A)

Another teacher offered emotional and motivational support by linking linguistic risk-taking to videos she played in the classroom, showing well-known inventors who went through thousands of failed product prototypes before achieving success.

Example 2:

So I have a whole bunch of videos that I present to them, and then we discuss, "Why is it important to take risks? Not just in French class, but in general. What does that give you? What does that teach? What can you get from them?" And so we have class discussions in French. So students who [are shy and] don't really talk get to listen to the conversation. And we always end up with concluding that it's important to take risks. It's hard. It's harder for some. But it's important. [...] In many situations, you have to overcome your shyness. And so that's why we work on that part at the beginning, is that, yes, it's a little bit embarrassing at times. It's a little bit frightening even. But you have to do it. At some point, you have to talk yourself into this [...] And they understand. I mean, even the shyest of the class understand the value of risk-taking that applies not just in French...

(Teacher B)

The same teacher also engages her students in ideal L2 visualization activities, cultivating an inner voice, and a growth mindset (cf. Dörnyei, 2015; Dweck, 2006) and uses these activities to encourage risk-taking.

Example 3:

"Of course I'm not able to do this. Of course it's difficult for me." But that inner voice. To work on their inner voice, to be able to talk themselves into it. Because there's no one else that will do it."

(Teacher B) 
Another teacher draws parallels with adventures or extreme sports in her effort to integrate emotional and motivational support.

\section{Example 4:}

I say, "Are you risk takers? How many of you have done bungee jumping or skydiving? Or how many of you are super athletes, extreme athletes?" And there's always a few hands. And I say, "Would you call yourself, would you categorize yourself as risk takers?" And a few hands go up. And then I say, "I think all of you are risk takers $[\ldots] "$

(Teacher C)

It is important to note how this teacher generalizes risk-taking to all learners, not just the ones who would describe themselves as risk-takers, which relates to one of the fundamental aspects of the passport's design as a dynamic tool. That is, the broad definition of risk and the multiple items listed allow all participants to be agents of their own learning through a meaningful selection of tasks that represent a risk for them, based on their individual linguistic, social, and emotional profile.

Related to the thrill of adventures and extreme sports from example 4, another teacher comments on a new dynamic that emerged in her classes where learners began to dare each other to take risks. She attributes this to a special ambiance that was unique to that particular group of learners but also underscores the emotional and motivational support that she offered through reflective activities (written reflections in this case).

Example 5:

Cette idée de "dare" que j'ai constatée dans la classe, je l'ai dit ouvertement, j'ai dit : "Écoutez, vous êtes dans un mode de défi, est-ce que ça change quelque chose à votre perception, à l'envie que vous avez de vous lancer dans des choses plus difficiles ?" Ce genre de réflexion...

This idea of a dare that I noticed in the class, I told them overtly, I said: 'Listen, you are in challenge mode, does this change something in your perception, in your eagerness to embark on things that are more difficult?' This type of reflection...

(Teacher E)

Overall, the emotional support demonstrated by these examples was not only related to negative emotions such as fear, stress or anxiety. The data indicate existing awareness of these factors but also highlight the positive aspects of linguistic risk-taking related to achievement and enjoyment. This duality of the construct is crucial to the Linguistic Risk-Taking Initiative, as indicated in sections 2-4 earlier.

The second subtheme of the classroom support theme relates to strategic support. The literature on strategies in language learning is extensive, and it is beyond the scope of this article to summarize it thoroughly (for an overview, see Oxford, 2017) but we generally see various types of strategies emerging in the data. Some of these strategies were aimed at managing anxiety and stress related to using the L2 in real life (e.g., taking a 
deep breath). Others were strategies related to time management and organization to help learners take risks outside the classroom (e.g., set phone reminders, set up weekly risktaking goals, etc.). A third type of strategy was communicative and included rehearsal, paraphrasing, and requests for clarification or repetition (for an overview of the classification of such strategies, see Dörnyei and Scott, 1997). For space considerations, we focus only on this third category of strategies and exemplify it below.

Teacher $\mathrm{C}$ discussed requests for repetition or clarification as a communication strategy that can be used when taking linguistic risks outside the classroom:

Example 6:

I tell my students all the time, "If you ask someone for clarification - 'Could you repeat that please?' - ask them to repeat it in a different way." Because they tend to say exactly the same thing. Well chances are if I didn't understand that the first time, I'm not going to get it the second time. Say it a different way.

(Teacher C)

This strategy emerged in the classroom context of discussing linguistic risk-taking and learners sharing feelings of fear of not being able to understand their interlocutor when using the L2 in real life. Another strategy that teachers overtly oriented to was paraphrasing by learners. Paraphrases were taught in the context of potential lexical gaps on the part of the L2 learner that may be a factor causing anxiety and thus preventing them from taking a risk and communicating in the $\mathrm{L} 2$ in real life:

\section{Example 7:}

I've also used that... example that if you don't know how to say tiger, but you know how to say lion and stripe, you can at least explain what you want to say. Developing the strategy of... where you explain a word $[. .$.$] with a sentence instead.$ Practicing that, giving synonyms or a definition, an explanation of what you're looking at.

(Teacher A)

A particularly important example where a teacher not only discussed or taught a strategy but developed pedagogical material to support it was offered by teacher A. That teacher found that learners often reported speaking on the phone and going to the bank as particularly high-risk tasks. In response to this perceived difficulty, this teacher created a role play classroom task where students had to prepare a script to book a hotel room for a week-long vacation, asking the hotel and the receptionist as many things as possible: activities that were available around the hotel, restaurants, prices, if pets were accepted, if room service was available, and so on. Students were divided into two groups, and the role play took place on their phones, with half of the group outside the building, and half of the group staying in the classroom. Teacher A described her role as follows: 


\section{Example 8:}

I was going back and forth between [the classroom and] outside. I was trying to check how it was going. I think they had fun with that because it was a bit different and a bit surprising, and they were a bit shy...to speak on the phone, also because I think they felt quite weird to be 10 people outside of the building all on the phone and all booking a room at a hotel, but I think they liked it... What I liked is that they gave me immediate feedback about the activity.

(Teacher A)

The students' feedback was characterized by the following statement: "Yes, but the problem is in real life we don't have a script" (Teacher A). This feedback, which points to students finding a lack of authenticity in the task allotted to them, is instructive. Teacher A responded to their feedback as follows:

\section{Example 9:}

This was my segue to talking about strategies. Why wouldn't you have a script if you have to make a phone call and you know in advance what you're going to talk about, if you know that you're going to have to book a room, if you know that you're going to have to ask questions about your bank account, if you know that you're going to have to make a call to ask about your phone bill. You know that there are some things that you're going to have to ask for, and you know what kind of vocab you're going to need in advance... Why not try to write down some questions in advance? Why not try to create some sort of a script? Even though you can't expect to know the answers that you're going to be given, you can at least know what kind of questions you want to ask and the words that you need to use and the words that you need to recognize when the other person uses them.

(Teacher A)

The strategic response described here falls under the general umbrella term of 'planning' or 'rehearsal'. Rehearsal tasks within the classroom have been discussed as part of a TBLT approach (see Ellis, 2009, for a summary); in this scenario, the rehearsal task is clearly linked with its real-world actualization triggered by one of the items included in the Linguistic RiskTaking Passport (i.e., speaking on the phone in an L2).

The last aspect of the classroom support theme relates to linguistic support. This subtheme emerged in regard to vocabulary activities that the teachers mentioned in regard to the Linguistic Risk-Taking Initiative (in addition to what was already hinted at in example 9).

\section{Example 10:}

You know that there are some things that you're going to have to ask for, and you know what kind of vocab you're going to need in advance, so why not search for vocab? [...] We started brainstorming what kind of questions you could have to ask [...] so we made two columns, and we practiced very specific vocabulary... 
Teacher D also mentioned vocabulary learning in regard to the implementation of the Linguistic Risk-Taking Passport.

Example 11:

I think I would like to do something where maybe they plan in small groups. They plan on taking a risk that's more difficult. [...]They can research the vocabulary that they might need, and things like that.

(Teacher D)

To summarize, the classroom support theme that emerged from the data illustrates how implementing the Linguistic Risk-Taking Initiative spurred various discussions and activities in the classroom aimed to help learners not only overcome fear or anxiety in using their L2 outside of the classroom but also to employ various strategies to facilitate their risk-taking in real life. This shows how teachers overall oriented to supporting learner autonomy, pushing students to get out of their comfort zone and establish a bridge between the classroom and the real world. This type of supported autonomy was mentioned explicitly by several teachers, as indicated below.

Example 12:

The idea is to kind of give them an incentive and guidelines to become more autonomous...

(Teacher A)

Example 13:

They need to discuss together the success of their goal-attaining. [...] L'autonomie ne se fait pas toute seule [“autonomy doesn't just happen by itself”].

(Teacher B)

Example 14:

...il faut qu'ils se montrent autonome [...] On n'est pas encore en autonomie, mais on sort de la salle de classe, on fait un pas vers l'utilisation réelle, et ce pas là est extrêmement difficile à faire pour les étudiants ou il ne vient pas automatiquement. [...] De semaine en semaine, ils essaient, ils essaient, ils essaient. Ils utilisent une fois, ils utilisent deux fois, et au bout de 60 fois ou peut-être 100 fois, ça peut devenir plus naturel. [...] Pousser l'étudiant à l'extérieur de la salle de classe [...] c'est très important.

...they have to show they are autonomous [...] They are not yet autonomous, but they get out of the classroom, they take a step towards real language use, and this step is extremely difficult [...] or it doesn't come automatically. [...] From week to week, they try, they try, they try. They use it once, they use it twice, and after 60 
times or maybe 100 times, it can become more natural. [...] Pushing the student out of the classroom [...] is very important.

(Teacher E)

Related to the idea of autonomy, one teacher offered the metaphor of linguistic risk-taking serving as a bridge between classroom learning and real-life L2 use:

Example 15:

Pour moi la valeur de l'initiative et du passeport est, justement, de créer des ponts, de créer des liens entre ce qui se passe dans la salle de classe et l'utilisation, de dire à l'étudiant: 'Écoute, ce qu'on est en train de travailler en salle de classe, ce n'est pas pour la salle de classe, c'est pour l'extérieur.'

For me, the value of the initiative and the passport is precisely to create bridges, to create links between what happens in the classroom and its use, to say to the student: 'Listen, what we are working on in the classroom, it is not for the classroom, it is for the outside.'

(Teacher E)

Thus, linguistic risk-taking should ideally work in tandem with classroom learning and support, as classroom learning may facilitate risk-taking outside of the classroom walls. We will return to the bridge metaphor in the discussion section.

\section{Theme 2: Learner Engagement: Interest and Personal Investment}

A second theme identified in the data relates to teacher reports of student engagement with the Linguistic Risk-Taking Initiative, suggesting personal interest and investment on the part of the learners. This was expressed in various ways, once again creating a multifaceted theme. One aspect of engagement was learners' desire to retain their passports as souvenirs after the end of the course.

Example 16:

But that passport also [is] a tool that you use often that will remind you of what you've done, where you've been. [...] And at the end of the course, when we do the draw, I have all the passports in a bag. And then at the end, I pull two, they win the prize, and then I ask [...] "So who wants to have their passport back?" They all raise their hands. They all want it back. They could say, "Oh, well that's okay. Keep it." Nope, they want it back. And so, to me, I think it's an indication that the passport has a sentimental value. And that's good, it's a positive thing.

(Teacher B)

Beyond the sentimental value that indicates engagement, learners who retain their passports may continue to use them as an autonomous learning tool after completing the course (a question we plan on investigating in future research). 
As another example of engagement, teacher E reported that linguistic risk-taking had turned into a daring game among her students (recall also example 5) and they started reporting authentic language use in what she perceived as very high-stakes situations in real life.

\section{Example 17:}

C'était un des étudiants qui a dit : "J'étais super malade... je suis allé au service de santé puis j'ai demandé les services importants [en FLS].” [rire]... Là tout le monde était comme : "Waouh." Puis on arrive. Moi je dis : "Écoute, tu prends des risques là parce que tu aurais pu sortir avec des médicaments que ne te conviennent pas" [rire]. C'est devenu comme un jeu de qu'est-ce que je peux faire d'extrême en français. [...] Il y a un [autre] étudiant qui a manqué les cours et qui avait dit : "Écoutez, j'ai le certificat médical pour vous, que j'ai demandé qu'on m'écrive en français parce que quand je suis allé aux services médicaux j'ai requis qu'on me serve en français. " Après ça, ce n'était pas tout le monde parce que c'est quand même une classe de 28 , mais aux trois semaines j'avais toujours un ou deux cas comme ça où je me dis : 'Waouh. C'est fabuleux.'

It was one of the students who said, 'I was super sick... so I went to the health centre and asked for an important service [in L2 French].' [laughs]. Everybody was like, 'Wow,' And there you go. And I said, 'Listen, you were really taking a risk there because you could have ended up with the wrong medication' [laughs]. It became like a game of what can I do in French that is more extreme. [...] There was one [other] student who missed classes and said, 'Look, I have the medical certificate for you, which I asked to be in French because when I went to the health services I asked to be served in French.' After that, it wasn't everybody because it's still a class of 28, but every three weeks I always had one or two cases like that where I'm like, 'Wow, this is fabulous.'

(Teacher E)

Another example of student engagement was offered by a teacher who asked learners to offer their reflections on the Linguistic Risk-Taking Initiative during the last class of the semester.

Example 18:

...it was a tool that encouraged them to put themselves in certain circumstances to push their linguistic abilities. I remember one student saying, "I never went to outings. But because it was one of the items [in the passport], I challenged myself that I have to go to an outing and used the language." Right. And same goes for the other items in the passport. [...] I could feel it in their voices when they were describing that. [...] the voice was trembling, and I could feel that maybe in those experiences, because they were challenged linguistically. So this translates into strong emotions as well $[. .$.$] they liked the fact that$ they were encouraged to challenge themselves, because of the passports. [...] So I could sense their emotions, and the challenges they experienced [...] And even the quieter students, they spoke out that day [...] It was a surprise to me. I've got to tell you that.

(Teacher F) 
Overall, these examples illustrate the learner engagement theme in various ways. Although the data represent teachers' perceptions and not the students' own voices, the examples are based on observable phenomena. That is, the students' explicit requests to retain their passports after the end of the course, the 'dare' game that one class initiated, and the trembling voices which suggested strong emotion all indicate a level of personal interest, agency and investment that was generated by the passport and witnessed by the teachers. The example in 18 above also mentions the teacher's surprise, which leads us to the next theme: teachers' own discoveries and growth.

\section{Theme 3: Teacher Growth: New Discoveries and Constantly Evolving Classroom Practices}

Throughout the interviews, teachers oriented to their own experiences with the Linguistic Risk-Taking Initiative mentioning new discoveries, evolving classroom practices and professional growth related to the participation in the project. Teacher $\mathrm{F}$, for example, indicated that he was surprised by students' strong emotions triggered by the passport, as already indicated above. This teacher mentioned that he was in fact quite skeptical about the project initially but decided to trial it and was pleasantly surprised afterwards.

Example 19:

I presented the purpose of the passports. Initially I was a bit doubtful myself, but I didn't express that. I was working with a group of students who were welcoming of new ideas. [...] I was a bit skeptical with regard to using the passports in the class. But I was proven wrong by the majority in the class. [...] The last [session] was the most surprising for me when I got the honest feedback, and I was surprised, because the mentality like, I was surprised. [...] So I think the majority, the majority work in favour of the passport. Why? Because it was a tool that encouraged them to put themselves in certain circumstances to push their linguistic abilities.

(Teacher F)

The teacher explicitly recognizes that his initial hesitation about the project was overtaken by the positive experiences that he believes his students had and in retrospect realized that this was a useful initiative. He further comments on how his wife is also a language learner and how she could also benefit from a tool like this.

Example 20:

So I always have linguistic discussions with my wife who's a second language speaker. When I was going through the items, it just reminded me of her. And somebody like her [...] She wouldn't be in the system here [...] But I think it would be useful for her as well [...] She would see it as a tool to reflect on her own emotions, and experiences. [...] I said [to myself], "Wow, I wish I could give one to my wife."

(Teacher F) 
This change of attitude over the course of a semester is indicative of reflective teacher practices, professional growth, and new methodological discoveries triggered by the project. The willingness to subsequently recommend the passport to a loved one suggests a real transformation from initial skepticism to a genuine belief in the potential of the tool.

Another teacher, who participated in the project over several semesters, comments that her classroom practices revolving around the passport have evolved and improved over time. This also suggests reflective practices and teacher growth related to implementing the initiative.

Example 21:

In these [two] years, I noticed that I changed the way I introduced the passport. It was really a progressive sort of a process. So at first, I just introduced the passport, passed it to students, explained to them the rationale behind it... I sort of assumed that they were going to be filling it out... and they were going to be independent. However, I noticed that it didn't work. They need support.

(Teacher B)

This example shows not only evidence of evolving teacher practices but also interconnects with the theme related to classroom support and building autonomy identified earlier (cf. Example 2).

Another teacher's comments suggest reflective practices and teacher growth by indicating that initially, she used the passport as a supplementary activity that was not in the course syllabus but that, over time, she saw more value in it and decided to integrate it formally in the syllabus.

\section{Example 22:}

So the first three times I did it, I didn't include it in my syllabus. But now it is part of the participation [...] That's a tangible way of, "Oh, you've done it. Check."

(Teacher C)

Finally, teacher D expressed some self-doubt about the way she initially implemented the initiative in her classes. In during her first semester teaching in the program, she introduced the passports to the learners late due to logistical reasons, and she felt that it was not successful. She also felt that the assignments that she decided to link to the passport were stressful for the students.

Example 23:

The first time, I really didn't do a good job because I ... It was my first term working in the program. I was trying to balance everything. The grammar, the textbook, then there's this thing. I wasn't sure how to do it, and the students didn't seem to respond to it very well.

(Teacher D) 
However, in her second semester, she modified the implementation of the initiative in her class and reported that it worked better.

Example 24:

I think [starting earlier] did make a difference, because it's also at the beginning of our term. Everything is ... You set up everything. [...] So, they have to choose three risks that they've taken. Talk about ... Well, explain the risks. Then how did it feel? Was it difficult? Would they do it again? If they did it again, how? [...] Their version of it, it's a lot of just stating this happened. They are just explaining what risk they took. Then there's questions, then I kind of go with the whole class, I'm like what about the rest of you guys? Did you take any new risks? [...] It's a lot of the same things though. It's a lot of oh, I watch Netflix. [...] Now I want to move on towards something that's more ...really pushing themselves. [...]

(Teacher D)

It is worth noting that even though the teacher felt the process improved in the second semester, the students still were not responding as well as she wanted them to, and she thus continued to reflect on new ways of engagement, as the example indicates.

\section{Results (RQ2): Which Items in the Passport Were Evaluated as Particularly High- Risk by the Students Participating in the Initiative?}

The aim of RQ2 was to identify the specific situations in which students may require the kind of additional support identified in the responses to RQ1 and to illustrate the passport's potential role as a needs analysis tool (the latter will be discussed in section 6 below). Table 1 shows the ten items in the passport that had the greatest proportions of being marked as 'high-risk' by the students who took them. 


\section{Table 1}

Risks taken as part of the Linguistic Risk-Taking Initiative with the greatest proportions marked as high

\begin{tabular}{|c|c|c|c|c|}
\hline $\begin{array}{l}\text { Ranking } \\
\#\end{array}$ & Risk & $\begin{array}{c}\text { No. of } \\
\text { times } \\
\text { risk } \\
\text { marked } \\
\text { H/M/L }\end{array}$ & $\begin{array}{c}\text { No. of } \\
\text { times } \\
\text { marked } \mathbf{H}\end{array}$ & $\begin{array}{c}\text { Proportion } \\
\text { of attempts } \\
\text { marked } \mathbf{H} \\
(\%)\end{array}$ \\
\hline 1 & I had a job interview in $\mathrm{E} / \mathrm{F}$ & 104 & 55 & 52.8 \\
\hline 2 & $\begin{array}{l}\text { I called a toll free number and chose } \\
\text { to be served in } \mathrm{E} / \mathrm{F}\end{array}$ & 62 & 32 & 51.6 \\
\hline 3 & $\begin{array}{l}\text { I enrolled in the Second Language } \\
\text { Certification Course }^{9}\end{array}$ & 42 & 18 & 42.9 \\
\hline 4 & $\begin{array}{l}\text { I applied for a job on the campus } \\
\text { where I will need to use E/F }\end{array}$ & 99 & 41 & 41.4 \\
\hline 5 & $\begin{array}{l}\text { I prepared a resume or cover letter } \\
\text { in } \mathrm{E} / \mathrm{F}\end{array}$ & 212 & 86 & 40.6 \\
\hline 6 & $\begin{array}{l}\text { I used } \mathrm{E} / \mathrm{F} \text { to speak to a high- } \\
\text { ranking } \mathrm{uOttawa} \text { official }\end{array}$ & 39 & 15 & 38.5 \\
\hline 7 & I left a voicemail in $\mathrm{E} / \mathrm{F}$ & 159 & 52 & 32.7 \\
\hline 8 & I made a phone call in $\mathrm{E} / \mathrm{F}$ & 348 & 113 & 32.5 \\
\hline 9 & I used $\mathrm{E} / \mathrm{F}$ at work & 237 & 76 & 32.1 \\
\hline 10 & $\begin{array}{l}\text { I contributed to an online } \\
\text { forum/discussion board in } \mathrm{E} / \mathrm{F}\end{array}$ & 50 & 16 & 32.0 \\
\hline
\end{tabular}

Note. E/F indicates English or French, according to the language in which the passport user is taking risks (i.e., the learner's target language).

Several commonalities emerge from Table 1. Risks involving spoken interaction (and, therefore, both speaking and listening skills) can be seen as dominant in this ranking. Preparing a resumé (\#5) and contributing to an online forum (\#10) draw on written skills, while using a second language at work (\#9) may draw on both spoken interaction and writing skills.

Both the domain and mode of language use (Biber, 1994) are also apparent: four risks concern the world of work $(\# 1, \# 4, \# 5)$, and three relate to communication on the telephone (\#2,\#7,\#8). All risks involve a third party in some way - whether the recipient of a voicemail, a manager in a job interview or the final assessment of the official language certification course. ${ }^{10}$ The inclusion of contributing to a message board (\#10) in the top ten may seem surprising at first sight, if one assumes that online interactions afford more distance and less discomfort due to the seemingly less personal act of posting a message. However, this more likely represents the possibility of being 'flamed' (criticized online) by fellow commentators in a forum.

Data from Table 1 show that $32.5 \%$ of students who made a phone call in their L2 reported it as a high-risk experience; furthermore, $51.6 \%$ of those calling a toll-free number in their L2 reported it as high-risk. This suggests that speaking on the phone in the L2, in general, is a challenging experience. The particular difference in these two percentages likely reflects the difference in domain of usage or interlocutor, with phone calls to toll- 
free numbers necessitating conversation with strangers in high-stakes situations (such as dealing with immigration, tax agencies, banks, etc.), as opposed to general phone calls with friends and family. ${ }^{11}$ This aspect of the quantitative data is corroborated by teachers' reports that students cited talking on the phone as one of the more stressful experiences in a second language. We have already shown in the interview data related to RQ1 how one teacher used this finding to develop a task-based response to this (recall Examples 7 \& 8) an example of a cyclical process which will be further discussed in the following section.

\section{Discussion}

Looking back at the overall results of the study, we found that the Linguistic RiskTaking Initiative triggered various aspects of classroom support offered by the teachers along emotional, strategic, and linguistic dimensions, ultimately pointing to the importance of building learner autonomy. In addition, teachers perceived the initiative as engaging for the students, citing specific examples that they found remarkable in terms of the power of emotions exhibited, eagerness to take on challenging tasks, and desire to retain the passport tool past the end of a semester course. For the teachers themselves, the initiative triggered professional growth through reflection, evolving practices, and new discoveries and realizations, sometimes overturning initial skepticism.

The data also illustrated how The Linguistic Risk-Taking Passport can identify which items constitute high-risk tasks for the learners. On the one hand, this may increase learners' own levels of awareness; on the other hand, teachers can use this as needs analysis, using discussions (qualitative data) as well as completed passports (quantitative data) to discover what tasks they may need to focus on in the classroom. While we acknowledge that risks are dynamic and a one-size-fits-all approach cannot be developed, a top-ten ranking of high risks for a group of learners can contribute to useful and targeted teaching practices and design of activities.

We have positioned the Linguistic Risk-Taking Passport as a tool that fits well within a broad TBLT framework. It draws TBLT researchers' and practitioners' attention to a dynamic subset of special tasks with emotional flavour, encapsulating both anxiety and enjoyment. We see this as an innovative approach that opens up opportunities for learner engagement in real-life L2 use, consistent with Ellis et al.'s (2020) argument that experiential learning, learner agency, interest, and investment have received relatively little attention in the TBLT literature.

In terms of the link between the classroom and the outside world, Teacher E's description of the potential for the passport to créer des ponts 'create bridges' between the classroom and the outside world calls to mind Dewaele's (2005) description of those challenging final steps towards autonomy:

Although well-informed teachers and appropriate material can contribute to a raising of the learners' awareness [...] the last leg of the learners' journey can only be unsupported. (p.377)

We view linguistic risk-taking tasks as part of a larger cyclical process connecting classroom learning to authentic real-world language use and vice versa. This process, schematically illustrated in Figure 3, may be of interest to the broad TBLT community. 
Figure 3

Integration of classroom practices and real-world linguistic risk-taking tasks

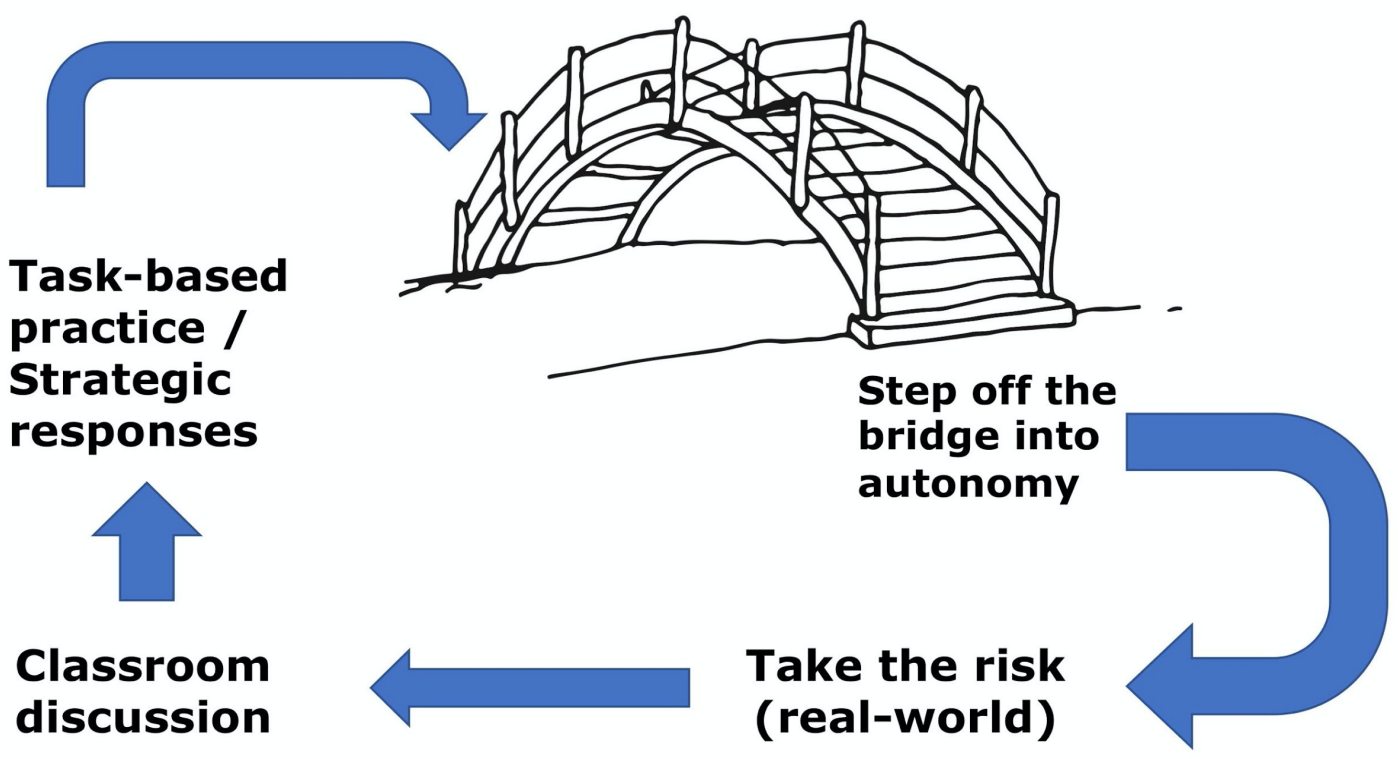

Note. Bridge image: Gabriel Jose/Shutterstock.com

Figure 3 shows that the cyclical nature of this process allows both for true autonomous language use and for continual support and scaffolding within the classroom. The observation that the last leg of the journey into autonomy is unsupported is relevant, but it can nevertheless be supported both before and after the fact. We recall our characterization of risks as learner-selected tasks which take place beyond the classroom. The drive to take these risks can only come from the learner's agency. However, returning these authentic language experiences to the classroom evokes MacIntyre \& Mercer's (2014) description of "settings in which communication and personally meaningful interactions are foregrounded" (p.154). We have seen that, as a result of these discussions, the classroom can offer task-based practice, strategic instruction, teacher and peer support, and a rare opportunity for learners to represent themselves as individuals engaged in the emotional process of moving towards autonomous L2 use.

\section{Pedagogical Implications}

While the findings and discussion in the previous sections drew on the results from RQ1 and RQ2, in this section, we turn to RQ3: What pedagogical implications can be drawn from insights generated through RQ1 and RQ2?

We offer a summary of learnings from the implementation of the Linguistic RiskTaking Initiative applicable not only to our ongoing institutional project but also to other institutions and classrooms. Thus, practitioners may wish to introduce linguistic risk-taking as a supplement to classroom teaching in a broad TBLT framework. 
1. The full list of items in the Linguistic Risk-Taking Passport can be found online at ccerbal.uottawa.ca/linguistic-risk. Teachers can easily obtain written permission and adapt it and create a tool for the context in which they teach. ${ }^{12}$

2. Draw on students' personal experiences when making this tool. Involve them in its creation. Have students propose additional risks.

3. Encourage students to identify as risk-takers by thinking of areas of their lives in which they have already taken risks.

4. Bring risk-taking into the classroom on a regular (e.g., weekly) basis. This can be an informal check-in, or a conversation structured around a specific theme (talking on the phone, going to the bank, etc.).

5. Introduce rehearsal tasks to the classroom in response to recurring themes of risks that learners have found challenging (using the tool for needs analysis).

6. Use risk-taking discussions as an opportunity to introduce communication strategies.

7. Acknowledge the affective resources which are necessary for L2 language use beyond the classroom and discuss anxiety management.

8. As well as looking back on risks taken, allow students to set goals (i.e., "This week I will attempt risks $\mathrm{X}, \mathrm{Y}$, and $\mathrm{Z}$, and next week I will share my experience with the class.").

Introduce planning strategies for lexis and grammar which may be encountered in these situations.

9. Examine the effect of repetition on risk-taking. Encourage students to engage with the same risk on multiple occasions and chart their progress (encourage selfreflection: "Did it become easier/less risky/more gratifying after I repeated risk X several times?").

10. Share examples of your own linguistic risk-taking as a teacher-learner. Allow yourself to discuss the emotions you have felt as an L2 user. Be a role model of imperfection (rather than projecting complete competence and error-free linguistic usage).

\section{Limitations, Future Research and Final Reflections}

Beyond this exploratory study, various additional quantitative and qualitative analyses need to be done to provide additional insight into linguistic risk-taking. The qualitative data in this study relies on teachers' beliefs as elicited in interviews, which do not always reflect the reality of the classroom (Borg, 2015). Accordingly, future study would be strengthened by classroom observations to report in more detail on usual practices in the classroom and examine them more carefully from a TBLT perspective. In terms of future plans for this ongoing project, we have recently developed a digital Linguistic Risk-Taking app that offers a host of additional affordances, such as learners' ability to review customized statistics tracking their progress over time, self-analysis of number and nature of risks taken, integrated goal-setting and reminders, integrated badges, achievement levels, rewards, and so on. This presents future opportunities for learner engagement through gamification as well as new opportunities for data collection and analysis. 
Correspondence should be addressed to Nikolay Slavkov.

Email: nikolay.slavkov@uottawa.ca

\section{Notes}

${ }^{1}$ We use the term L2 as it is commonly used at the institution where the project takes place; we acknowledge that in reality what is dubbed L2 can be the third, fourth, etc. language in a learner's repertoire.

2 The project also draws insights from the literature on gamification, which are not discussed in this article due to space considerations and because they relate to a later development of the Initiative.

3 The passport was first piloted in the Fall 2017 semester with 61 pre-determined risks. It was expanded to include 74 risks in the three subsequent semesters examined in this paper. A current version with an even higher number of risks is available for download at ccerbal.uottawa.ca/linguistic-risk/.

${ }^{4}$ Of course, we acknowledge that pedagogical interventions based on the concept of WTC do exist.

${ }^{5}$ We thank an anonymous reviewer for bringing up this point to help further our argument.

${ }^{6}$ In effect, a technically more accurate title for the passport would be "A passport with potential linguistic risks", recognizing explicitly the dynamics of the construct. For the purposes of learner engagement and catchiness of the title, "Linguistic Risk-Taking Passport" was selected.

${ }^{7}$ Feedback from users showed that the relatively high percentage of data where risk level values were not indicated was at least partly due to the visual design of the passport (i.e., the H/M/L marking instructions were not prominent enough). Since 2019, we have redesigned the checkboxes to make the need to select a risk level more explicit and an analysis of future data will show if the response rate increases in this regard. Furthermore, the phone app subsequently designed for this project contains validation coding which resolves this issue (i.e., risk level $\mathrm{H} / \mathrm{M} / \mathrm{L}$ must be checked before a risk can be marked as taken). Data generated through the app will also be available for future research.

${ }^{8}$ The institution also allows graduate students to enroll in undergraduate language classes (usually less than $10 \%$ per class).

9 This risk involves enrolling in a certification course at the university's language centre, which represents a significant time commitment and a willingness to undergo a rigorous assessment at the end. We acknowledge it can be seen as anomalous in the list of risks but also highlight that this is a special course with emphasis on autonomous preparation for the certificate at our institution and as such linguistic risk-taking activities constitute a significant part of it. 
${ }^{10}$ By mentioning third-party communication, we note that risks such as those related to reading a book or a newspaper or listening to podcasts are not included. As such, tasks that are marked as high-risk seem to involve third-party communication.

${ }^{11}$ Speaking to a family member in the L2 may seem unusual or unnatural. However, some of our participants had both francophone and anglophone relatives. For example, an anglophone participant reported calling a francophone relative with whom he would normally speak in English but decided to speak to that relative in French because of the Linguistic Risk-Taking Passport.

${ }^{12}$ Our team can be contacted for the required written permission and funding acknowledgements.

\section{Acknowledgements}

We thank two anonymous reviewers for their insightful and considered feedback on a previous version of this article. Thanks are due to Marie-Josée Hamel for her comments on a previous presentation of the data in this paper. Our work has also benefited from helpful comments and suggestions offered by the audiences of the 2019 ACLA/CAAL Conference, the 2019 TBLT Conference, and the 2019 SSU3 Conference. We are grateful to the members of the Linguistic Risk-Taking Research Group at the Official Languages and Bilingualism Institute of the University of Ottawa for continued support and inspiration. Internal financial support for this project at the University of Ottawa has been received from the Vice-President Academic and Provost's Office and from the Research Chair on Language Management (Sylvie Lamoureux). Public acknowledgement of external financial support / Reconnaissance publique de l'appui financier externe: This project has been made possible in part by the Government of Canada (Canadian Heritage, Enhancement of Official Languages Program) / Ce projet a été rendu possible en partie grâce au gouvernement du Canada (Patrimoine canadien, Programme Mise en valeur des langues officielles).

\section{References}

Auerbach, C. F., \& Silverstein, L. B. (2003). Qualitative data: An introduction to coding and analysis. New York University Press.

Beebe, L. M. (1983). Risk-taking and the language learner. In H. W. Seliger \& M. H. Long (Eds.), Classroom oriented research in second language acquisition (pp.39-66). Newbury House.

Benson, P. (2011). What's new in autonomy. The Language Teacher, 35(4), 15-18. Benson, P., \& Reinders, H. (2011). Beyond the language classroom. Palgrave Macmillan. Biber, D. (1994). An analytical framework for register studies. In D. Biber \& E. Finegan (Eds.), Sociolinguistic perspectives on register (pp.31-56). Oxford University Press. 
Borg, S. (2015). Researching teachers' beliefs. In B. Paltridge and A. Phakiti (Eds.), Research methods in Applied Linguistics. Bloomsbury Academic.

Boyatzis, R. E. (1998). Transforming qualitative information: Thematic analysis and code development. SAGE Publications.

Cervantes, I. M. (2013). The role of risk-taking behavior in the development of speaking skills in ESL classrooms. Revista de Lenguas Modernas, 19, 421-435.

Coste, D., Moore, D., \& Zarate, G. (2009). Plurilingual and pluricultural competence. Council of Europe.

Cotterall, S. (2000). Promoting learner autonomy through the curriculum: Principles for designing language courses. ELT Journal, 54(2), 109-117.

https://doi.org/10.1093/elt/54.2.109

Council of Europe. (2001). Common European framework of reference for languages: Learning, teaching, assessment. Cambridge University Press.

Council of Europe. (2018). Common European framework of reference for languages: Learning, teaching, assessment. Companion volume with new descriptors. Council of Europe.

Csikszentmihalyi, M., \& Nakamura, J. (2011). Positive psychology: Where did it come from, where is it going? In M. K. Sheldon, T. B. Kashdan, \& M. F. Steger (Eds.), Designing positive psychology: Taking stock and moving forward (pp.3-8). Oxford University Press.

Dewaele, J.-M. (2005). Investigating the psychological and emotional dimensions in instructed language learning: Obstacles and possibilities. The Modern Language Journal, 89(3), 367-380. https://doi.org/10.1111/j.1540-4781.2005.00311.x

Dewaele, J.-M., \& MacIntyre, P. D. (2016). Foreign language enjoyment and foreign language classroom anxiety. The right and left feet of FL learning? In P. MacIntyre, T. Gregersen and S. Mercer (Eds.), Positive Psychology in SLA (pp.215-236). Multilingual Matters.

Dewaele, J.-M., Witney, J., Saito, K., \& Dewaele, L. (2018). Foreign language enjoyment and anxiety: The effect of teacher and learner variables. Language Teaching Research, 22(6), 676-697. https://doi.org/10.1177/1362168817692161

Dörnyei, Z., \& Scott, M. L. (1997). Communication strategies in a second language: Definitions and taxonomies. Language Learning, 47, 173-210.

Duff, P. (2017). Language socialization. In N. H. Hornberger \& S. L. McKay (Eds.), Sociolinguistics and language education (pp.427-454). Multilingual Matters.

Duff, P. A., \& Talmy, S. (2011). Language socialization approaches to second language acquisition: Social, cultural, and linguistic development in additional languages. In D. Atkinson (Ed.), Alternative approaches to second language acquisition (pp.95116). Routledge.

Dweck, C. S. (2006). Mindset: The new psychology of success (1st ed.). Random House.

Ellis, R. (2009). Task-based language teaching: Sorting out the misunderstandings. International Journal of Applied Linguistics, 19, 221-246.

Ellis, R., \& Shintani, N. (2014). Exploring language pedagogy through second language acquisition research. Routledge.

Ellis, R., Skehan, P., Li, S., Shintani, N., \& Lambert, C. (2020). Task-based language teaching: Theory and practice. Cambridge University Press. 
Gass, S. M., \& Mackey, A. (2015). Input, interaction and output in second language acquisition. In B. VanPatten \& J. Williams (Eds.), Theories in second language acquisition: An introduction (pp.180-206). Routledge.

Jackson, J. (2018). Interculturality in international education. Routledge.

Kogan, N., \& Wallach, M. A. (1967). Risk taking as a function of the situation, the person, and the group. In New Directions in Psychology III. Holt, Rinehart and Winston.

Lambert, C. (2017). Tasks, affect and second language performance. Language Teaching Research, 21(6), 657-664. https://doi.org/10.1177/1362168817736644

Lambert, C., Philp, J., \& Nakamura, S. (2017). Learner-generated content and engagement in second language task performance. Language Teaching Research, 21(6), 665680. https://doi.org/10.1177/1362168816683559

Littlewood, W. (1999). Defining and developing autonomy in East Asian contexts. Applied Linguistics, 20(1), 71-94. https://doi.org/10.1093/applin/20.1.71

Long, M. H. (1985). A role for instruction in second language acquisition: Task-based language teaching. In K. Hyltenstam \& M. Pienemann (Eds.), Modelling and assessing second language acquisition (pp.77-99). Multilingual Matters.

Long, M. H. (1996). The role of the linguistic environment in second language acquisition. In W. Ritchie and T. Bhatia (Eds.), Handbook of second language acquisition. (pp.413-468). Academic Press.

Lopez, S. J., \& Snyder, C. R. (2009). Oxford handbook of positive psychology. Oxford University Press.

MacIntyre, P. D. (2012). The idiodynamic method: A closer look at the dynamics of communication traits. Communication Research Reports, 29(4), 361-367. https://doi.org/10.1080/08824096.2012.723274

MacIntyre, P. D. (2017). An overview of language anxiety research and trends in its development. In Ch. Gkonou, M. Daubney \& J.-M. Dewaele (Eds.), New insights into language anxiety: Theory, research and educational implications (pp.11-30). Multilingual Matters.

MacIntyre, P. D., Burns, C., \& Jessome, A. (2011). Ambivalence about communicating in a second language: A qualitative study of French Immersion students' willingness to communicate. The Modern Language Journal, 95(1), 81-96. https://doi.org/10.1111/j.1540-4781.2010.01141.x

MacIntyre, P. D., Clément, R., Dörnyei, Z., \& Noels, K. A. (1998). Conceptualizing willingness to communicate in a L2: A situational model of L2 confidence and affiliation. The Modern Language Journal, 82(4), 545-562. https://doi.org/10.1111/j.1540-4781.1998.tb05543.x

MacIntyre, P. D., \& Mercer, S. (2014). Introducing positive psychology to SLA. Studies in Second Language Learning and Teaching, 4, 153-172. https://doi.org/10.14746/ssllt.2014.4.2.2

Nunan, D. (1991). Communicative tasks and the language curriculum. TESOL Quarterly, 25(2), 279-295.

Nunan, D. (2004). Task-based language teaching. Cambridge University Press.

Nunan, D. (2010). A task-based approach to materials development. Advances in Language and Literary Studies, 1(2), 135-160. https://doi.org/10.7575/aiac.alls.v.1n.2p.135

Nunan, D., \& Lockwood, J. (1991). The Australian English course: Task-based English for post-beginners. Cambridge University Press. 
Nunan, D., \& Richards, C. (2015). Language learning beyond the classroom. Routledge.

Ochs, E., \& Schieffelin, B. (2008). Language socialization: An historical overview. In P. A. Duff \& N. H. Hornberger (Eds.), Language socialization: Encyclopedia of language and education. Vol. 8 (2nd ed., pp. 3-15). Springer.

Oxford, R. L. (2017). Teaching and researching language learning strategies: Selfregulation in context. Routledge.

Peterson, C. (2006). A primer in positive psychology. Oxford University Press.

Saldaña, J. (2016). The coding manual for qualitative researchers ( $3^{\text {rd }}$ ed.). Sage Publications.

Seligman, M. E. P., \& Csikszentmihalyi, M. (2000). Positive psychology: An introduction. American Psychologist, 55(1), 5-14. https://doi.org/doi:10.1037/0003-066X.55.1.5

Slavkov, N. (2020). Where the magic happens: Fostering language learning, bilingualism and multilingualism through linguistic risk-taking. In T. Tinnefeld (Ed.), The magic of language: productivity in linguistics and language teaching. Vol. 11 (pp.47-69). htw saar. https://sites.google.com/site/linguistikunddidaktik/home

Slavkov, N., \& Séror, J. (2019). The development of the linguistic risk-taking initiative at a bilingual post-secondary institution in Canada. Canadian Modern Language Review, 75(3), 254-271. https://doi.org/10.3138/cmlr.2018-0202

Wei, L., \& Moyer, M. G. (2008). The Blackwell guide to research methods in bilingualism and multilingualism. John Wiley \& Sons. 


\section{Appendix A}

\section{Protocol for semi-structured interviews with teachers}

A. Practicalities. Should we run the initiative every year? Should it be every semester or just once a year? Should we focus on a particular level? Are students feeling pressured to take part? Why do you think students take part? Should it be optional?

B. Student perceptions of risks. What are your observations of students' perceptions of linguistic risks? Are there any common themes to situations students feel are big risks? What strategies do students use when planning to take a risk?

C. Implementation. How do you integrate the idea of risk taking and the passport into your teaching? How regularly is risk-taking discussed in your classroom? How do you encourage participation?

D. Classroom support and strategy instruction. Do you teach students strategies they can use in difficult communicative situations? How do you think we can support students in taking more linguistic risks? Is there a useful role for a classroom discussion about communication strategies?

E. Reflection. What works well in the passport? What can be improved? Have any memorable student experiences arisen as a result of using the passport? Can you describe a student (actual or imagined) who is a successful user of the passport? And what about a student who has struggled with it, or not used it? 